\title{
Genetic Variations in the Kir6.2 Subunit (KCNJ11) of Pancreatic ATP-Sensitive Potassium Channel Gene Are Associated with Insulin Response to Glucose Loading and Early Onset of Type 2 Diabetes in Childhood and Adolescence in Taiwan
}

\author{
Yi-Der Jiang, ${ }^{1}$ Lee-Ming Chuang, ${ }^{1,2}$ Dee Pei, ${ }^{3}$ Yann-Jinn Lee, ${ }^{4}$ \\ Jun-Nan Wei, ${ }^{5}$ Fung-Chang Sung, ${ }^{6}$ and Tien-Jyun Chang ${ }^{1}$ \\ ${ }^{1}$ Department of Internal Medicine, National Taiwan University Hospital, 7 Chung-Shan South Road, Taipei 10002, Taiwan \\ ${ }^{2}$ Graduate Institute of Preventive Medicine, School of Public Health, National Taiwan University, Taipei 10002, Taiwan \\ ${ }^{3}$ Division of Endocrinology and Metabolism, Department of Internal Medicine, Cardinal Tien Hospital, Xindian 23148, Taiwan \\ ${ }^{4}$ Department of Pediatrics, Mackay General Hospital, Taipei 10449, Taiwan \\ ${ }^{5}$ Chia Nan University of Pharmacy and Science, Tainan 71710, Taiwan \\ ${ }^{6}$ Institute of Environmental Health, College of Public Health, China Medical University, Taichung 40447, Taiwan
}

Correspondence should be addressed to Tien-Jyun Chang; tjc922@gmail.com

Received 2 May 2014; Accepted 20 August 2014; Published 21 September 2014

Academic Editor: Jyuhn-Huarng Juang

Copyright (c) 2014 Yi-Der Jiang et al. This is an open access article distributed under the Creative Commons Attribution License, which permits unrestricted use, distribution, and reproduction in any medium, provided the original work is properly cited.

\begin{abstract}
To investigate the role of E23K polymorphism of the KCNJ11 gene on early onset of type 2 diabetes in school-aged children/adolescents in Taiwan, we recruited 38 subjects with type 2 diabetes (ages $18.6 \pm 6.6$ years; body mass index percentiles $83.3 \pm 15.4$ ) and 69 normal controls (ages $17.3 \pm 3.8$ years; body mass index percentiles $56.7 \pm 29.0$ ) from a national surveillance for childhood/adolescent diabetes in Taiwan. We searched for the E23K polymorphism of the KCNJ11 gene. We found that type 2 diabetic subjects had higher carrier rate of E23K polymorphism of KCNJ11 gene than control subjects $(P=0.044)$. After adjusting for age, gender, body mass index percentiles, and fasting plasma insulin, the E23K polymorphism contributed to an increased risk for type 2 diabetes $(P=0.047)$. K23-allele-containing genotypes conferring increased plasma insulin level during OGTT in normal subjects. However, the diabetic subjects with the K23-allele-containing genotypes had lower fasting plasma insulin levels after adjustment of age and BMI percentiles. In conclusion, the E23K variant of the KCNJ11 gene conferred higher susceptibility to type 2 diabetes in children/adolescents. Furthermore, in normal glucose-tolerant children/adolescents, K23 allele carriers had a higher insulin response to oral glucose loading.
\end{abstract}

\section{Introduction}

Diabetes mellitus in children and adolescents has long been considered primarily type 1 diabetes. Although type 2 diabetes (T2D) is generally considered to be a disease of adults, the past 15-20 years have seen a dramatic increase in the prevalence of T2D in children and adolescents [1-9]. This increased prevalence of pediatric T2D suggests impending future morbidity from diabetic complications in a large number of relatively young adults.

In a nationwide surveillance program with mass urine screening in Taiwan $[10,11]$, the incidence of T2D is 6 times that of type 1 diabetes in recent years. The identified risk factors for T2D in youth are similar to those for adult type 2 diabetes with the most prominent risk of childhood obesity for T2D [11]. T2D is generally believed to be a polygenic disorder, with disease development being influenced by both hereditary and environmental factors [12]. Genetic factors are important in determining the children who become obese and also the obese children who develop T2D [13]. Support for the role of genetic factors comes from epidemiological evidence that T2D in youth is most common in individuals from racial groups with a high prevalence of diabetes and in individuals with a strong family history [14]. A search for 
the contribution of certain candidate genes in the early onset T2D is mandatory for further understanding of pathogenesis of T2D in childhood.

The pancreatic islet ATP-sensitive potassium channel complex $\left(\mathrm{K}_{\mathrm{ATP}}\right)$ plays a major role in glucose-stimulated insulin secretion, thus serving as a strong candidate for T2D. This channel is a heterooctameric complex composed of four sulfonylurea receptor (SUR1) subunits and four Kir6.2 subunits $[15,16]$. Mutations in the SUR1 $(A B C C 8)$ and the Kir6.2 (KCNJ11) cause familial hyperinsulinemia in infancy [17], while some polymorphisms in these genes (exon 16-3t/c and exon $18 \mathrm{C} / \mathrm{T}$ of $A B C C 8$ and E23K of KCNJ11) have been reported to be associated with $\mathrm{T} 2 \mathrm{D}$ in several populations at different degrees [18-23]. The K23 allele is associated with higher risk of $\mathrm{T} 2 \mathrm{D}$, providing an overall odds ratio (OR) of 1.23 [23] and 1.26 [21] in Caucasians and Asians, respectively. According to a recent systemic meta-analysis, the E23K polymorphism was significantly associated with increased T2D risk with per-allele odds ratio (OR) of 1.12. When stratified by ethnicity, significantly increased risks were found for the polymorphism in Caucasians and East Asians. However, no such associations were detected among Indian and other ethnic populations [24]. Normoglycemic lysine carriers are shown to consistently display a defect in insulin secretion [23, 25, 26]. Furthermore, the codon 23 KCNJ11 polymorphism is shown to be related to glucose intolerance in Caucasians and progression from glucose intolerance to T2D [27, 28].

Recent studies have provided evidence that the E23K variant alters channel function by inducing spontaneous overactivity of pancreatic $\beta$-cells, thus increasing the threshold of ATP concentration for insulin release $[29,30]$. Therefore, in this study, we analyzed the E23K polymorphism of KCNJ11 gene in a group of subjects with T2D and a group of controls identified in a nationwide surveillance program for diabetes in schoolchildren aged $6 \sim 18$ in Taiwan. We demonstrated that the E23K polymorphism of KCNJ11 gene increased susceptibility to T2D in childhood and adolescence.

\section{Materials and Methods}

2.1. Subjects. With a nationwide surveillance program for diabetes in Taiwanese school-aged children, 137 subjects were newly diagnosed with T2D [10, 11]. Only 38 newly diagnosed T2D subjects and 69 nondiabetic subjects from the northern part of Taiwan were recruited for genetic analysis. Body mass index (BMI) is a measure of body fat based on body height $(\mathrm{BH})$ and body weight (BW) (BMI $\left.=\mathrm{BW}(\mathrm{kg}) / \mathrm{BH}^{2}\left(\mathrm{~m}^{2}\right)\right)$. After BMI is calculated for children and teens, the BMI number is plotted on the Centers for Disease Control and Prevention (CDC) BMI-for-age growth charts (for either girls or boys) to obtain a percentile ranking (http://www.cdc.gov/healthyweight/assessing/bmi/childrens_bmi/about_childrens_bmi.html, searched on 8.14.2014). A standard oral glucose tolerance test with 1.75 g glucose $/ \mathrm{kg}$ of body weight or maximally with $75 \mathrm{~g}$ glucose was performed to classify the state of glucose tolerance, except for subjects diagnosed with a fasting plasma glucose level equal to or over $126 \mathrm{mg} / \mathrm{dL}$. Informed consent was obtained from each participant and their parents of those under 18. This study was approved by the Institutional Review Boards.

2.2. Measurements of Metabolic Parameters. The fasting plasma glucose, serum insulin, cholesterol, and TG were measured according to the previous reports [31]. Insulin resistance index was calculated with homeostasis model assessment (HOMA-IR) as described previously [32]. The estimated $\beta$-cell function based on the HOMA-B was calculated based on the following formula: $\% \mathrm{~B}=20 \times$ fasting plasma insulin (FPI, $\mu \mathrm{U} / \mathrm{mL}$ )/(fasting plasma glucose (FPG, $\mathrm{mM})-3.5$ ) [33]. Another set of estimates of $\beta$-cell function proposed by Stumvoll et al. was also calculated using the two formulae: 1 st $\mathrm{PH}_{\mathrm{s}}=1283+(1.829 \times$ plasma insulin concentration at $30 \mathrm{~min})-(138.7 \times$ plasma glucose concentration at $30 \mathrm{~min})+(3.772 \times \mathrm{FPI})$ and $2 \mathrm{nd} \mathrm{PH}_{\mathrm{s}}=287+(0.4164 \times$ plasma insulin concentration at $30 \mathrm{~min})-(26.07 \times$ plasma glucose concentration at $30 \mathrm{~min})+(0.9226 \times \mathrm{FPI})$. These estimations were based on plasma glucose concentrations in $\mathrm{mmol} / \mathrm{L}$ and plasma insulin concentrations in $\mathrm{pmol} / \mathrm{L}$ [34]. Insulinogenic index (30 minutes) was estimated as follows: (Ins 30 - Ins 0)/(Glu 30 - Glu 0) [35]. Area under curve (AUC) of glucose and insulin during OGTT was also calculated.

2.3. Genotyping for the Polymorphism of KCNJ11. The E23K polymorphism of KCNJ11 was genotyped by PCR-restriction fragment length polymorphism (PCR-RFLP). PCR was performed with forward primer $5^{\prime}$-GACTCTGCAGTGAGGCCCTA- $3^{\prime}$ and reverse primer $5^{\prime}$-ACGTTGCAGTTGCCTTTCTT $-3^{\prime}$ starting with a denaturing step at $95^{\circ} \mathrm{C}$ for $3 \mathrm{~min}$ followed by 35 cycles of $95^{\circ} \mathrm{C}$ for $30 \mathrm{~s}$, annealing at $60^{\circ} \mathrm{C}$ for $30 \mathrm{~s}$, and elongation at $72^{\circ} \mathrm{C}$ for $30 \mathrm{~s}$ with a final elongation step at $72^{\circ} \mathrm{C}$ for $9 \mathrm{~min}$. The PCR product was $209 \mathrm{bps}$, and it was digested with BanII (New England Biolabs, Beverly, MA) and separated on $3 \%$ agarose gels. The substitution of $\mathrm{G}$ with A eliminated the BanII site.

2.4. Statistical Analysis. Data were represented as mean $\pm \mathrm{SD}$. Due to relatively small sample size, EK/KK were grouped together for regression analyses. Fisher's exact test was used to detect the distribution difference between diabetic and nondiabetic groups. Logistic regression model was further performed to adjust demographic difference. Student's $t$-test was applied to compare the difference of various parameters between different genotypes or between normal control and diabetic subjects. MANOVA was applied to compare the difference of glucose and insulin levels during OGTT test between different genotypes. SAS program version 8.1 (SAS institute Inc., Cary, NC) was applied for statistical analyses. A value of $P<0.05$ was considered statistically significant.

\section{Results}

3.1. Demographic and Metabolic Characteristic. The demographic and metabolic data of the study subjects are shown in Table 1. Obesity, dyslipidemia, higher fasting plasma insulin, 
TABLE 1: Clinical and metabolic features between normal controls and type 2 diabetic subjects in the present study.

\begin{tabular}{lccc}
\hline & Non-DM $(n=69)$ & DM $(n=38)$ & $P$ value \\
\hline Age (years) & $17.3 \pm 3.8$ & $18.6 \pm 6.6$ & 0.289 \\
BMI percentiles & $56.7 \pm 29.0$ & $83.8 \pm 15.4$ & $<0.001$ \\
Glucose (mmol/L) & $5.19 \pm 0.40$ & $10.65 \pm 4.05$ & $<0.001$ \\
TCH (mmol/L) & $4.05 \pm 0.77$ & $4.22 \pm 1.02$ & 0.4159 \\
TG (mmol/L) & $0.74 \pm 0.26$ & $1.17 \pm 0.45$ & 0.0005 \\
HDL (mmol/L) & $1.43 \pm 0.39$ & $1.20 \pm 0.50$ & 0.0320 \\
Fasting insulin (pmol/L) & $7.66 \pm 4.47$ & $17.99 \pm 20.43$ & 0.0043 \\
HOMA-IR & $1.78 \pm 1.06$ & $7.48 \pm 8.09$ & $<0.001$ \\
Log (HOMA-IR) & $0.402 \pm 0.624$ & $1.449 \pm 1.143$ & $<0.001$ \\
HOMA-B & $94.62 \pm 58.17$ & $94.13 \pm 168.52$ & $3.490 \pm 1.458$ \\
Log (HOMA-B) & $4.372 \pm 0.625$ & $20: 18$ & 0.987 \\
Sex (M:F) & $26: 43$ & 0.001 & \\
\hline
\end{tabular}

${ }^{*} P$ value with Student's $t$-test.

$\$$ By chi-squared test.

BMI percentiles: body mass index age- and sex-specific percentiles; TCH: total cholesterol; TG: triglyceride; HDL: high density lipoprotein-cholesterol; HOMAIR: homeostasis model assessment-insulin resistance; HOMA-B: homeostasis model assessment- $\beta$ cell.

TABle 2: Genotypic distribution of E23K polymorphism of the Kir6.2 between normal control and type 2 diabetes subjects.

\begin{tabular}{|c|c|c|c|c|c|}
\hline & Non-DM $(n=69)$ & $\mathrm{DM}(n=38)$ & $P$ value* & Odds ratio & 95\% confidence interval \\
\hline \multicolumn{6}{|l|}{ Genotype* } \\
\hline $\mathrm{EE}, n(\%)$ & $24(34.8 \%)$ & $6(15.8 \%)$ & & & \\
\hline $\mathrm{EK} / \mathrm{KK}, n(\%)$ & $45(65.2 \%)$ & $32(84.2 \%)$ & 0.044 & 2.84 & $1.04-7.75$ \\
\hline \multicolumn{6}{|l|}{ Allele } \\
\hline E-allele, $n(\%)$ & $81(58.7 \%)$ & $38(50.0 \%)$ & & & \\
\hline K-allele, $n(\%)$ & $57(41.3 \%)$ & $38(50.0 \%)$ & 0.251 & 1.42 & $0.81-2.50$ \\
\hline
\end{tabular}

${ }^{*}$ Chi-squared test.

higher insulin resistance, and worsened $\beta$-cell function were found in subjects with $\mathrm{T} 2 \mathrm{D}$ in childhood and adolescence (Table 1).

3.2. Genotypes of KCNJ11 Genes. As shown in Table 2, Kallele-containing genotypes were significantly higher in subjects with T2D as compared to those of control $(84.2 \%$ versus $65.2 \%, P=0.044$ ) (Table 2 ). To further adjust for potential confounding variables, logistic regression analysis was performed (Table 3). After adjustment of age, sex, and BMI age- and sex-specific percentiles (model 1), we found that higher BMI percentiles is an independent risk factor of type 2 diabetes (odds ratio $=1.060,95 \%$ CI: 1.027-1.094, and $P<0.001)$. If we adjust for age, sex, BMI age- and sexspecific percentiles, and fasting plasma insulin levels (model 2 ), the K-allele-containing genotype is an independent risk factor of type 2 diabetes (odds ratio $=4.105$, 95\% CI: $1.0008-$ 16.831 , and $P=0.047$ ). The fasting plasma insulin levels and BMI age- and sex-specific percentiles are also independent risk factors for T2D (odds ratio $=1.066,95 \%$ CI: $1.001-1.135$, and $P=0.045$ for fasting insulin; odds ratio $=1.047,95 \%$ CI: 1.014-1.080 for BMI age- and sex-specific percentiles, and $P=0.004$, resp.).

3.3. Effect of E23K Polymorphism of the KCNJ11 in Normal Glucose-Tolerant Subjects. To study the effect of genetic polymorphism of the E23K on insulin and glucose homeostasis during oral glucose tolerance test, we firstly compared those with EE genotype and the K23-allele-containing genotypes (EK or KK) in the normal glucose-tolerant subjects. There was no difference in the glucose levels during OGTT between subjects with different genotypes (Figure 1(a)). In contrast, subjects with EK/KK genotypes did have a significantly higher level of plasma insulin level at $60 \mathrm{~min}$ after glucose loading and higher AUC of insulin during OGTT (Figure 1(b)). However, this association of genotype of KCNJ11 with plasma insulin levels at $60 \mathrm{~min}$ after glucose loading became insignificant after adjustment of age, sex, and BMI percentiles.

3.4. Effect of E23K Polymorphism of the KCNJ11 on Clinical Phenotypes in Diabetic and Nondiabetic Subjects. To further search for the features of E23K variants on development of type 2 diabetes in children and adolescents, we then compared various metabolic parameters between those with EE genotype and the K23-allele-containing genotypes (EK or KK) in both diabetic and nondiabetic subjects (Table 4). In general, the fasting insulin levels were higher in diabetes group. However, the diabetic subjects with the K23-allelecontaining genotypes had a borderline significantly lower level of fasting plasma insulin than the diabetic subjects without K23 allele. With adjustment for age and BMI age- and sex-specific percentiles, the diabetic subjects with K-allelecontaining genotypes had significantly lower fasting plasma 
TABLE 3: Logistic regression analysis with type 2 diabetic status as dependent variables, age, sex, BMI age- and sex-specific percentiles, and genotype of E23K polymorphism in Kir6.2 as independent variables.

\begin{tabular}{lcc}
\hline Independent variables & Odds ratio & $95 \%$ CI \\
\hline Model 1 & & $P$ value \\
EK/KK versus EE & 2.941 & $0.764-11.323$ \\
Age (every 1 year increment) & 1.156 & $0.920-1.454$ \\
Sex (male = 1, female = 2) & 0.672 & $0.224-2.019$ \\
BMI age- and sex-specific percentiles (every 1 percentile increment) & 1.060 & $1.027-1.094$ \\
Model 2 & & 0.214 \\
EK/KK versus EE & 4.105 & $1.0008-16.831$ \\
Age (every 1 year increment) & 1.240 & $0.960-1.601$ \\
Sex (male = 1, female = 2) & 0.826 & $0.252-2.711$ \\
BMI age- and sex-specific percentiles (every 1 percentile increment) & 1.047 & $\mathbf{0 . 0 4 7}$ \\
Fasting plasma insulin levels (every 1 pmol/L increment) & 1.066 & 0.099 \\
\hline
\end{tabular}

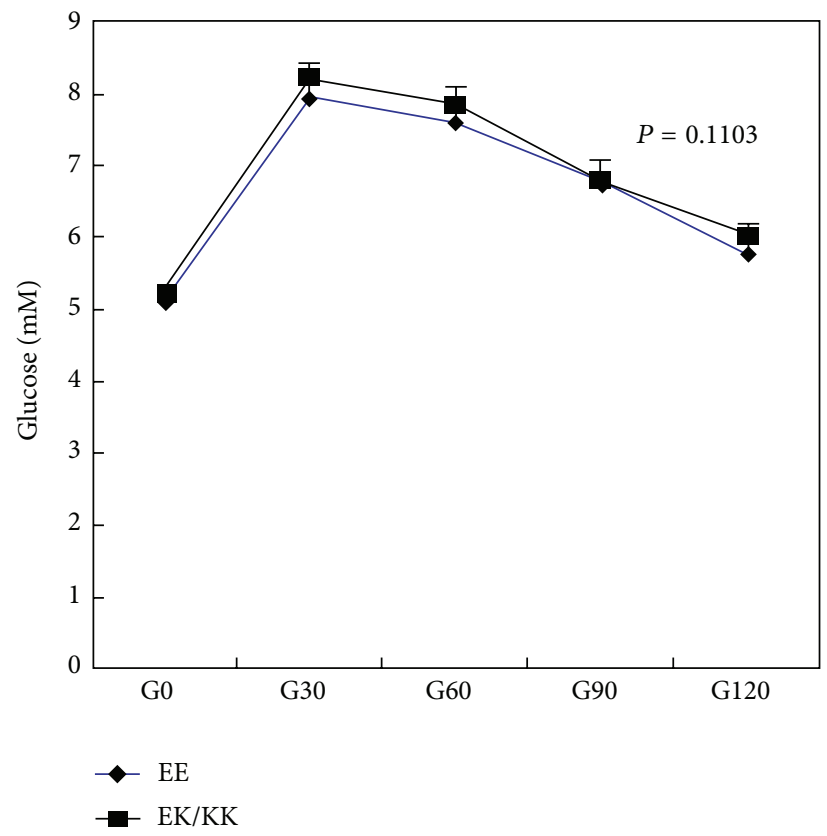

(a)

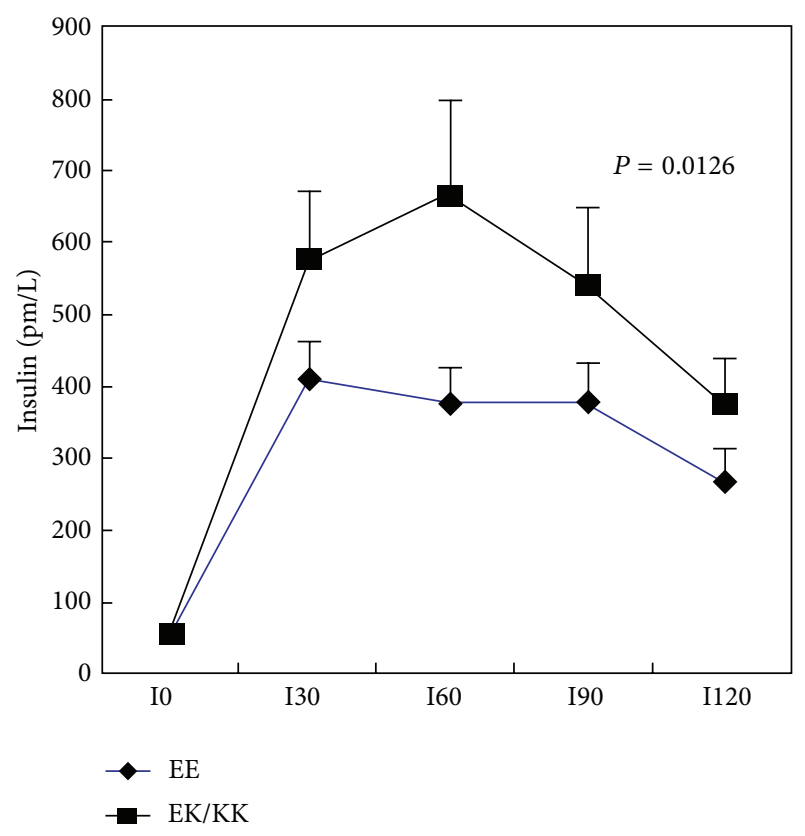

(b)

FIGURE 1: Glucose and insulin homeostasis during OGTT in the normal glucose-tolerant subjects according to genotypes of the KCNJ11 gene. There was no significant difference in plasma glucose levels in subjects with EE genotype compared with those with K23-allele-containing genotypes (EK or KK) (a). Subjects with EK/KK genotypes tended to have a higher level of plasma insulin level during OGTT (b). * indicates significant difference between the two groups.

insulin levels (fasting plasma insulin as dependent variable: $\beta$ for age: $-2.958 \pm 1.385, P=0.043 ; \beta$ for BMI age- and sex-specific percentiles: $0.548 \pm 0.238, P=0.030 ; \beta$ for $\mathrm{E} / \mathrm{E}$ or $\mathrm{E} / \mathrm{K}+\mathrm{K} / \mathrm{K}$ genotype: $-21.451 \pm 10.312, P=0.046)$. In contrast, there were no significant differences of these metabolic parameters between the K23-allele-containing and the EE genotype subjects in the nondiabetic group.

\section{Discussion}

In our present study, we found that a common polymorphism of E23K of the KCNJ11 confers higher susceptibility to T2D in childhood and adolescence of the Han-Chinese in Taiwan.
Childhood obesity is the single most important risk factor for type 2 diabetes in our schoolchildren $[10,11]$ and the present study. In the present study, we found that even with adjustment for age, sex, BMI age- and sex-specific percentiles, and fasting plasma insulin level, the K-allelecontaining genotypes (EK and $\mathrm{KK}$ ) confer an independent risk, with a relative high odds ratio of 4.105 , for $\mathrm{T} 2 \mathrm{D}$ in youth. Until recently, the Pro12Ala polymorphism in the peroxisome proliferator-activated receptor gamma (PPARG) was one of the other few polymorphisms that demonstrated an alteration in type 2 diabetes susceptibility across different populations [36]. More recently, several genome-wide association studies (GWAS) independently confirmed the strong 
TABLE 4: Clinical and metabolic features between those with E/E genotype and K-containing allele among type 2 diabetic and nondiabetic subjects, respectively.

\begin{tabular}{|c|c|c|c|c|c|c|}
\hline \multirow[b]{2}{*}{ Genotypes } & \multicolumn{3}{|c|}{ Type 2 diabetic subjects } & \multicolumn{3}{|c|}{ Nondiabetic subjects } \\
\hline & $\mathrm{E} / \mathrm{E}(n=6)$ & $\mathrm{E} / \mathrm{K}+\mathrm{K} / \mathrm{K}(n=32)$ & $P$ value* & $\mathrm{E} / \mathrm{E}(n=24)$ & $\mathrm{E} / \mathrm{K}+\mathrm{K} / \mathrm{K}(n=45)$ & $P$ value* \\
\hline $\operatorname{Sex}(M: F)$ & $4: 2$ & $16: 16$ & $0.663^{\$}$ & $11: 13$ & $15: 30$ & $0.434^{\$}$ \\
\hline Age (years) & $21.5 \pm 9.7$ & $18.0 \pm 5.8$ & 0.242 & $17.2 \pm 3.3$ & $17.4 \pm 4.1$ & 0.861 \\
\hline BMI age- sex-specific percentiles & $84.02 \pm 22.07$ & $83.73 \pm 14.31$ & 0.970 & $56.65 \pm 25.63$ & $56.79 \pm 30.87$ & 0.987 \\
\hline Glucose (mmol/L) & $10.0 \pm 3.8$ & $10.8 \pm 4.1$ & 0.715 & $5.1 \pm 0.4$ & $5.2 \pm 0.4$ & 0.133 \\
\hline Fasting plasma insulin levels (pmol/L) & $237.21 \pm 230.48$ & $112.18 \pm 126.24$ & 0.076 & $52.2 \pm 31.1$ & $56.5 \pm 32.8$ & 0.602 \\
\hline Ins-30' & - & - & & $414.67 \pm 53.23$ & $582.09 \pm 94.71$ & 0.222 \\
\hline Ins-60' & - & - & & $381.81 \pm 51.51$ & $671.57 \pm 132.39$ & 0.046 \\
\hline Ins-90' & - & - & & $379.09 \pm 55.41$ & $545.79 \pm 107.51$ & 0.280 \\
\hline Ins- $120^{\prime}$ & - & - & & $268.32 \pm 48.95$ & $375.18 \pm 67.10$ & 0.283 \\
\hline AUC-glucose & - & - & & $832.92 \pm 21.83$ & $855.72 \pm 17.02$ & 0.422 \\
\hline AUC-insulin & & & & $40074.46 \pm 4153.74$ & $60457.87 \pm 10721.20$ & 0.180 \\
\hline HOMA-B & $127.0 \pm 194.8$ & $89.89 \pm 168$ & 0.685 & $97.69 \pm 70.03$ & $92.98 \pm 51.55$ & 0.751 \\
\hline
\end{tabular}

${ }^{*} P$ value with Student's $t$-test.

${ }^{\$} P$ value with Fisher's exact test.

associations of SNP rs7903146 in the TCF7L2 locus with type 2 diabetes [37-40]. Evidence accumulated so far suggests that the E23K polymorphism of the KCNJ11 gene, which encodes the Kir6.2 subunit of the $\mathrm{K}_{\mathrm{ATP}}$ channel, is a candidate gene for type 2 diabetes reported mostly from adults [24, 41]. In children, one recent study indicated that six single nucleotide polymorphisms, including an activating R201H mutation on KCNJ11 gene, contribute to permanent neonatal diabetes [42]. Besides, several mutations on KCNJ11 gene have been reported to cause permanent hyperinsulinemic hypoglycemia of infancy [43-45]. A recent study reported that E23K variant did not affect metabolic disorders in prepubertal children who is small for gestational age at birth [46]. On the other hand, the association of the E23K polymorphism with type 1 diabetes was not statistically significant in the evaluated Korean population [47]. To our knowledge, no study has been reported for the impact of E23K polymorphism of the KCNJ11 gene on the early onset type 2 diabetes in children/adolescents. In consistence with previous studies in adult populations, we showed that schoolaged children/adolescents with T2D in this study had higher E23K carrier rate of KCNJ11 gene than normal subjects. According to Genetic Power Calculator (S. Purcell et al., 2003; http://pngu.mgh.harvard.edu/ purcell/gpc/), the estimated number of diabetic cases for $80 \%$ power will be 181 with $P$ value less than 0.05 . Though only 38 diabetic subjects were recruited in our study group, the E23K polymorphism still contributed to a significantly increased risk for type 2 diabetes independent of age, gender, BMI age- and sex-specific percentiles, and fasting plasma insulin level. Furthermore, from the meta-analysis of candidate-gene studies and GWAS for T2D in adults, the average odds ratio of each genetic variant to increased T2D risk is in the range from 1.10 to 1.37 [48]. According to a recent systemic meta-analysis, the E23K polymorphism was significantly associated with increased T2D risk with per-allele odds ratio (OR) of 1.12. However, in this study, the odds ratio of K-allele of KCNJ11 to increased T2D risk in childhood and adolescence reached 4.105 after adjusting age, gender, BMI age- and sex-specific percentiles, and fasting plasma insulin levels. It inferred that the E23K polymorphism of KCNJ11 contributed a much higher risk to T2D in children and adolescence than in adults.

How E23K variation leads to diabetes is not completely understood. In previous studies, it has been shown that insulin secretion is significantly reduced in both heterozygous $(\mathrm{E} / \mathrm{K})$ and homozygous $(\mathrm{K} / \mathrm{K})$ variants among the normal glucose-tolerant adults $[49,50]$. In contrast, we found that those carrying K-allele exhibited a higher insulin response after oral glucose loading in the normal glucosetolerant children (Figure 1(b)). In support of our findings, studies in the glucose-tolerant offspring of T2D patients carrying the E23K variants demonstrated significantly higher 2-hour insulin concentrations compared with those with control subjects [51]. Moreover, the E23K variant has been linked to an increase in BMI in the Danish population [50]. Taken together, these data including ours suggest that the higher response in insulin secretion to oral glucose loading might be due to the compensatory hypersecretion of insulin to maintain normal glucose homeostasis in the presence of insulin resistance. In spite of the small case number in this study, we found that there is a decline in fasting plasma insulin levels in diabetes subjects carrying $\mathrm{K}$-alleles compared to those with homozygous EE genotype when adjusted for age, sex, and BMI age- and sexspecific percentiles. Whether the reduced fasting insulin levels observed in the diabetic children/adolescents with K23allele-containing genotypes are due to inadequate compensation of $\beta$-cell failure is not known. Future longitudinal study will be required to establish the effect of E23K polymorphism in the KCNJ11 gene on changes of body build, insulin resistance, and $\beta$-cell dysfunction during disease progression. 


\section{Conclusions}

In conclusion, a common E23K variant of the KCNJ11 gene conferred higher susceptibility to T2D in children/adolescents in Taiwan. Furthermore, in the normal glucosetolerant children and adolescents, K23 allele carriers had a significantly higher insulin response to oral glucose loading, suggesting a compensatory insulin secretion in the presence of insulin resistance. However, the functional impact of the E23K polymorphism on progression of glucose intolerance and diabetes needs further investigation.

\section{Conflict of Interests}

The authors report no conflict of interests.

\section{Authors' Contribution}

Yi-Der Jiang, Lee-Ming Chuang, Tien-Jyun Chang, Jun-Nan Wei, and Fung-Chang Sung participated in concept/design. Lee-Ming Chuang, Dee Pei, and Yann-Jinn Lee participated in the collection of clinical and laboratory data. Yi-Der Jiang, Lee-Ming Chuang, and Tien-Jyun Chang participated in data analysis/interpretation and drafting of the paper. TienJyun Chang participated in critical revision of the paper and approval of the paper. Yi-Der Jiang and Lee-Ming Chuang contributed equally to this work.

\section{Acknowledgments}

The authors thank the staff of the Eighth Core Lab, Department of Medical Research, National Taiwan University Hospital, for technical support during the study. This work was supported by the Grant NSC 91-3112-B-002-019 from the National Science Council of Taiwan.

\section{References}

[1] R. Kahn, “Type 2 diabetes in children and adolescents," Diabetes Care, vol. 23, no. 3, pp. 381-389, 2000.

[2] D. Dabelea, R. A. Bell, R. B. D’Agostino Jr. et al., "Incidence of diabetes in youth in the United States," Journal of the American Medical Association, vol. 297, no. 24, pp. 2716-2724, 2007.

[3] E. J. Mayer-Davis, R. A. Bell, D. Dabelea et al., "The many faces of diabetes in American youth: Type 1 and type 2 diabetes in five race and ethnic populations: the SEARCH for diabetes in youth study," Diabetes Care, vol. 32, supplement 2, pp. S99-S101, 2009.

[4] L. L. Liu, J. P. Yi, J. Beyer et al., "Type 1 and type 2 diabetes in Asian and Pacific Islander U.S. youth. The SEARCH for diabetes in youth study," Diabetes Care, vol. 32, supplement 2, pp. S133S140, 2009.

[5] D. Dabelea, J. DeGroat, C. Sorrelman et al., "Diabetes in Navajo youth: prevalence, incidence, and clinical characteristics: the SEARCH for Diabetes in Youth Study," Diabetes Care, vol. 32, supplement 2, pp. S141-S147, 2009.

[6] J. M. Lawrence, E. J. Mayer-Davis, K. Reynolds et al., "Diabetes in Hispanic American youth: prevalence, incidence, demographics, and clinical characteristics: the SEARCH for Diabetes in Youth Study," Diabetes Care, vol. 32, supplement 2, pp. S123S132, 2009.
[7] R. A. Bell, E. J. Mayer-Davis, J. W. Beyer et al., "Diabetes in nonhispanic white youth," Diabetes Care, vol. 32, supplement 2, pp. S102-S111, 2009.

[8] H. Dean, "NIDDM-Y in first nation children in Canada," Clinical Pediatrics, vol. 37, no. 2, pp. 89-96, 1998.

[9] T. Kitagawa, M. Owada, T. Urakami, and N. Tajima, "Epidemiology of type 1 (insulin-dependent) and type 2 (non-insulindependent) diabetes mellitus in Japanese children," Diabetes Research and Clinical Practice, vol. 24, pp. S7-S13, 1994.

[10] J.-N. Wei, L.-M. Chuang, C.-C. Lin, C.-C. Chiang, R.-S. Lin, and F.-C. Sung, "Childhood diabetes identified in mass urine screening program in Taiwan, 1993-1999," Diabetes Research and Clinical Practice, vol. 59, no. 3, pp. 201-206, 2003.

[11] J.-N. Wei, F.-C. Sung, C.-C. Lin, R.-S. Lin, C.-C. Chiang, and L.-M. Chuang, "National surveillance for type 2 diabetes mellitus in Taiwanese children," Journal of the American Medical Association, vol. 290, no. 10, pp. 1345-1350, 2003.

[12] K. S. Polonsky, J. Sturis, and G. I. Bell, "Non-insulin-dependent diabetes mellitus - a genetically programmed failure of the beta cell to compensate for insulin resistance," The New England Journal of Medicine, vol. 334, no. 12, pp. 777-783, 1996.

[13] O. Gill-Carey and A. T. Hattersley, "Genetics and type 2 diabetes in youth," Pediatric Diabetes, vol. 8, no. 9, pp. 42-47, 2007.

[14] Ó. Rubio-Cabezas and J. Argente, "Current insights into the genetic basis of diabetes mellitus in children and adolescents," Journal of Pediatric Endocrinology and Metabolism, vol. 21, no. 10, pp. 917-940, 2008.

[15] L. Aguilar-Bryan, J. P. Clement IV, G. Gonzalez, K. Kunjilwar, A. Babenko, and J. Bryan, "Toward understanding the assembly and structure of K(ATP) channels," Physiological Reviews, vol. 78, no. 1, pp. 227-245, 1998.

[16] T. Miki, K. Nagashima, and S. Seino, "The structure and function of the ATP-sensitive $\mathrm{K}^{+}$channel in insulin-secreting pancreatic $\beta$-cells," Journal of Molecular Endocrinology, vol. 22, no. 2, pp. 113-123, 1999.

[17] N. Sharima, A. Crane, G. Gonzalez, J. Bryan, and L. AguilarBryan, "Familial hyperinsulinism and pancreatic $\beta$-cell ATPsensitive potassium channels," Kidney International, vol. 57, no. 3, pp. 803-808, 2000.

[18] A. L. Gloyn, Y. Hashim, S. J. Ashcroft et al., "Association stud ies of variants in promoter and coding regions of beta-cell ATP sensitive K-channel genes SUR1 and Kir6.2 with Type 2 diabetes mellitus (UKPDS 53)," Diabetes Medicines, vol. 18, no. 3, pp. 206-212, 2001.

[19] A. L. Gloyn, M. N. Weedon, K. R. Owen et al., "Large-scale association studies of variants in genes encoding the pancreatic $\beta$-cell KATP channel subunits Kir6.2 (KCNJ11) and SUR1 (ABCC8) confirm that the KCNJ11 E23K variant is associated with type 2 diabetes," Diabetes, vol. 52, no. 2, pp. 568-572, 2003.

[20] J. C. Florez, K. A. Jablonski, S. E. Kahn et al., “Type 2 diabetesassociated missense polymorphisms KCNJ11 E23K and ABCC8 A1369S influence progression to diabetes and response to interventions in the diabetes prevention program," Diabetes, vol. 56, no. 2, pp. 531-536, 2007.

[21] Y. Sakamoto, H. Inoue, P. Keshavarz et al., "SNPs in the KCNJ11$\mathrm{ABCC} 8$ gene locus are associated with type 2 diabetes and blood pressure levels in the Japanese population," Journal of Human Genetics, vol. 52, no. 10, pp. 781-793, 2007.

[22] Y. Doi, M. Kubo, T. Ninomiya et al., "Impact of Kir6.2 E23K polymorphism on the development of type 2 diabetes in a general Japanese population: the Hisayama study," Diabetes, vol. 56, no. 11, pp. 2829-2833, 2007. 
[23] E. M. Nielsen, L. Hansen, B. Carstensen et al., “The E23K variant of Kir6.2 associates with impaired post-OGTT serum insulin response and increased risk of type 2 diabetes," Diabetes, vol. 52, no. 2, pp. 573-577, 2003.

[24] L. Qiu, R. Na, R. Xu et al., "Quantitative assessment of the effect of KCNJ11 gene polymorphism on the risk of type 2 diabetes," PLoS One, vol. 9, no. 4, Article ID e93961, 2014.

[25] J. C. Florez, N. Burtt, P. I. W. de Bakker et al., "Haplotype structure and genotype-phenotype correlations of the sulfonylurea receptor and the islet ATP-sensitive potassium channel gene region," Diabetes, vol. 53, no. 5, pp. 1360-1368, 2004.

[26] V. Lyssenko, P. Almgren, D. Anevski et al., "Genetic prediction of future type 2 diabetes," PLoS Medicine, vol. 2, no. 12, article e345, 2005.

[27] R. M. Van Dam, B. Hoebee, J. C. Seidell, M. M. Schaap, T. W. A. De Bruin, and E. J. M. Feskens, "Common variants in the ATPsensitive K+ channel genes KCNJ11 (Kir6.2) and ABCC8 (SUR1) in relation to glucose intolerance: population-based studies and meta-analyses," Diabetic Medicine, vol. 22, no. 5, pp. 590-598, 2005.

[28] O. Laukkanen, J. Pihlajamäki, J. Lindström et al., "Polymorphisms of the SUR1 (ABCC8) and Kir6.2 (KCNJ11) genes predict the conversion from impaired glucose tolerance to type 2 diabetes. The Finnish Diabetes Prevention Study," Journal of Clinical Endocrinology and Metabolism, vol. 89, no. 12, pp. 62866290, 2004.

[29] C. Schwanstecher, U. Meyer, and M. Schwanstecher, "KIR6.2 Polymorphism predisposes to type 2 diabetes by inducing overactivity of pancreatic $\beta$-cell ATP-sensitive $\mathrm{K}^{+}$channels," Diabetes, vol. 51, no. 3, pp. 875-879, 2002.

[30] M. J. Riedel and P. E. Light, "Saturated and cis/trans unsaturated acyl CoA esters differentially regulate wild-type and polymorphic $\beta$-cell ATP-sensitive $\mathrm{K}^{+}$channels," Diabetes, vol. 54 , no. 7, pp. 2070-2079, 2005.

[31] W.-S. Yang, W.-J. Lee, T. Funahashi et al., "Weight reduction increases plasma levels of an adipose-derived antiinflammatory protein, adiponectin," The Journal of Clinical Endocrinology \& Metabolism, vol. 86, no. 8, pp. 3815-3819, 2001.

[32] D. R. Matthews, J. P. Hosker, A. S. Rudenski, B. A. Naylor, D. F. Treacher, and R. C. Turner, "Homeostasis model assessment: insulin resistance and $\beta$-cell function from fasting plasma glucose and insulin concentrations in man," Diabetologia, vol. 28, no. 7, pp. 412-419, 1985.

[33] J. C. Levy, D. R. Matthews, and M. P. Hermans, "Correct homeostasis model assessment (HOMA) evaluation uses the computer program," Diabetes Care, vol. 21, no. 12, pp. 2191-2192, 1998.

[34] M. Stumvoll, A. Mitrakou, W. Pimenta et al., "Use of the oral glucose tolerance test to assess insulin release and insulin sensitivity," Diabetes Care, vol. 23, no. 3, pp. 295-301, 2000.

[35] Y. Seino, M. Ikeda, M. Yawata, and H. Imura, "The insulinogenic index in secondary diabetes," Hormone and Metabolic Research, vol. 7, no. 2, pp. 107-115, 1975.

[36] D. Altshuler, J. N. Hirschhorn, M. Klannemark et al., "The common PPAR $\gamma$ Prol2Ala polymorphism is associated with decreased risk of type 2 diabetes," Nature Genetics, vol. 26, no. 1, pp. 76-80, 2000.

[37] R. Sladek, G. Rocheleau, J. Rung et al., "A genome-wide association study identifies novel risk loci for type 2 diabetes," Nature, vol. 445, no. 7130, pp. 881-885, 2007.

[38] Diabetes Genetics Initiative of Broad Institute of Harvard and MIT, Lund University, and Norvatis Inst itutes for BioMedical Research, "Genome-wide association analysis identifies loci for type 2 diabetes and triglyceride levels," Science, vol. 316, no. 5829, pp. 1331-1336, 2007.

[39] E. Zeggini, M. N. Weedon, C. M. Lindgren et al., "Replication of genome-wide association signals in UK samples reveals risk loci for type 2 diabetes," Science, vol. 316, no. 5829, pp. 1339-1341, 2007.

[40] L. J. Scott, K. L. Mohlke, L. L. Bonnycastle et al., "A genome-wide association study of type 2 diabetes in finns detects multiple susceptibility variants," Science, vol. 316, no. 5829, pp. 1341-1345, 2007.

[41] L. Love-Gregory, J. Wasson, J. Lin, G. Skolnick, B. Suarez, and M. A. Permutt, "An E23K single nucleotide polymorphism in the islet ATP-sensitive potassium channel gene (Kir6.2) contributes as much to the risk of Type II diabetes in Caucasians as the PPAR $\gamma$ Prol2Ala variant (3)," Diabetologia, vol. 46, no. 1, pp. 136-137, 2003.

[42] A. L. Gloyn, E. R. Pearson, J. F. Antcliff et al., "Activating mutations in the gene encoding the ATP sensitive potassium channel subunit Kir6.2 and permanent neonatal diabetes," New England Journal Medicine, vol. 350, no. 18, pp. 1838-1849, 2004.

[43] P. Thomas, Y. Ye, and E. Lightner, "Mutation of the pancreatic islet inward rectifier Kir6.2 also leads to familial persistent hyperinsulinemic hypoglycemia of infancy," Human Molecular Genetics, vol. 5, no. 11, pp. 1809-1812, 1996.

[44] A. Nestorowicz, N. Inagaki, T. Gonoi et al., "A nonsense mutation in the inward rectifier potassium channel gene, Kir6.2, is associated with familial hyperinsulinism," Diabetes, vol. 46, no. 11, pp. 1743-1748, 1997.

[45] E. Marthinet, A. Bloc, Y. Oka et al., "Severe congenital hyperinsulinism caused by a mutation in the Kir6.2 subunit of the adenosine triphosphate-sensitive potassium channel impairing trafficking and function," Journal of Clinical Endocrinology and Metabolism, vol. 90, no. 9, pp. 5401-5406, 2005.

[46] R. Stawerska, M. Szalapska, M. Borowiec et al., "Frequency of the E23K polymorphism of the KCNJ11 gene in children born small for gestational age and its influence on auxological and metabolic parameters in the prepubertal period," Journal of Pediatric Endocrinology and Metabolism, vol. 26, no. 5-6, pp. 457-462, 2013.

[47] J. M. Ko, S. Yang, S. Y. Kim, H. S. Lee, J. S. Hwang, and I. T. Hwang, "E23K polymorphism of the KCNJ11 gene in Korean children with type 1 diabetes," World Journal of Pediatrics, vol. 8, no. 2, pp. 169-172, 2012.

[48] T. M. Frayling, "Genome-wide association studies provide new insights into type 2 diabetes aetiology," Nature Reviews Genetics, vol. 8, no. 9, pp. 657-662, 2007.

[49] J. C. Florez, N. Burtt, P. I. W. de Bakker et al., "Haplotype structure and genotype phenotype correlations of the sulfonylurea receptor and the islet ATP sensitive potassium channel gene region," Diabetes, vol. 53, no. 5, pp. 1360-1368, 2004.

[50] E.-M. D. Nielsen, L. Hansen, B. Carstensen et al., "The E23K variant of Kir6.2 associates with impaired post-OGTT serum insulin response and increased risk of type 2 diabetes," Diabetes, vol. 52, no. 2, pp. 573-577, 2003.

[51] C. E. Ezenwaka, R. Kalloo, M. Uhlig, R. Schwenk, and J. Eckel, "The E23K variant in the Kir6.2 subunit of the ATP-sensitive $\mathrm{K}+$ channel does not augment impaired glucose tolerance in Caribbean subjects with a family history of type 2 diabetes," Journal of Endocrinology, vol. 185, no. 3, pp. 439-444, 2005. 


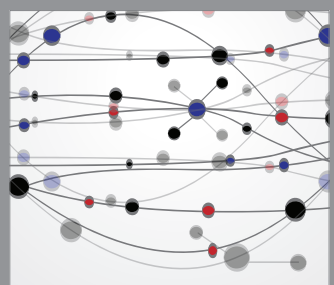

The Scientific World Journal
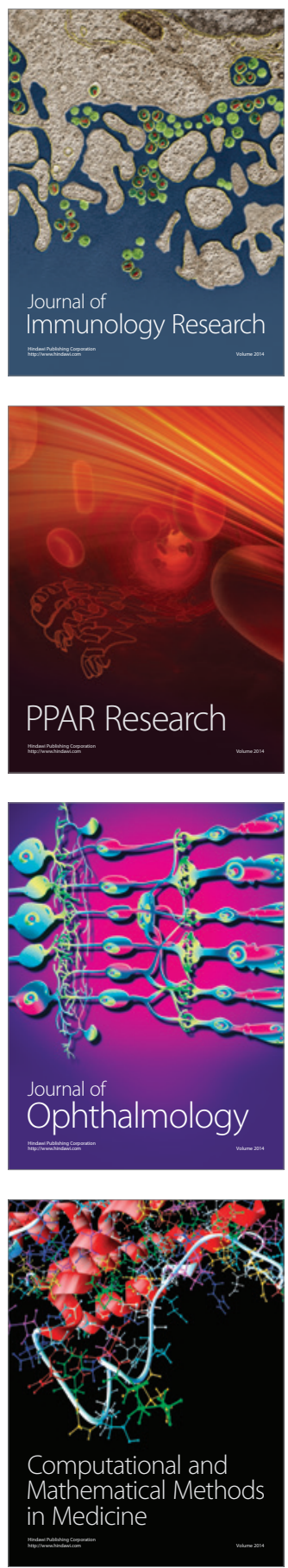

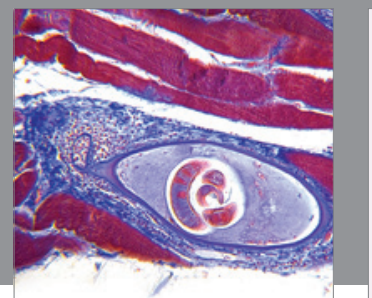

Gastroenterology

Research and Practice
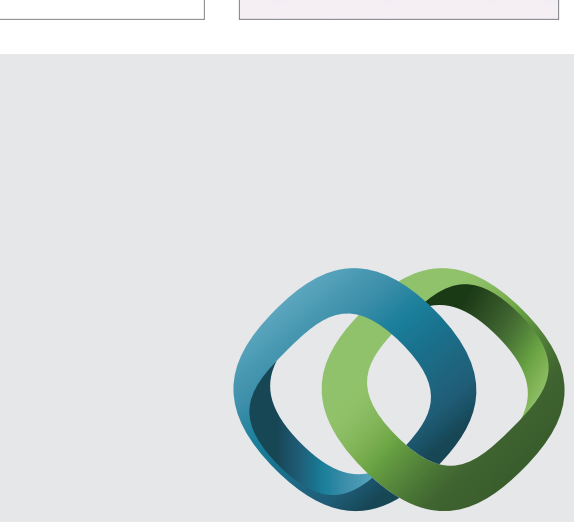

\section{Hindawi}

Submit your manuscripts at

http://www.hindawi.com
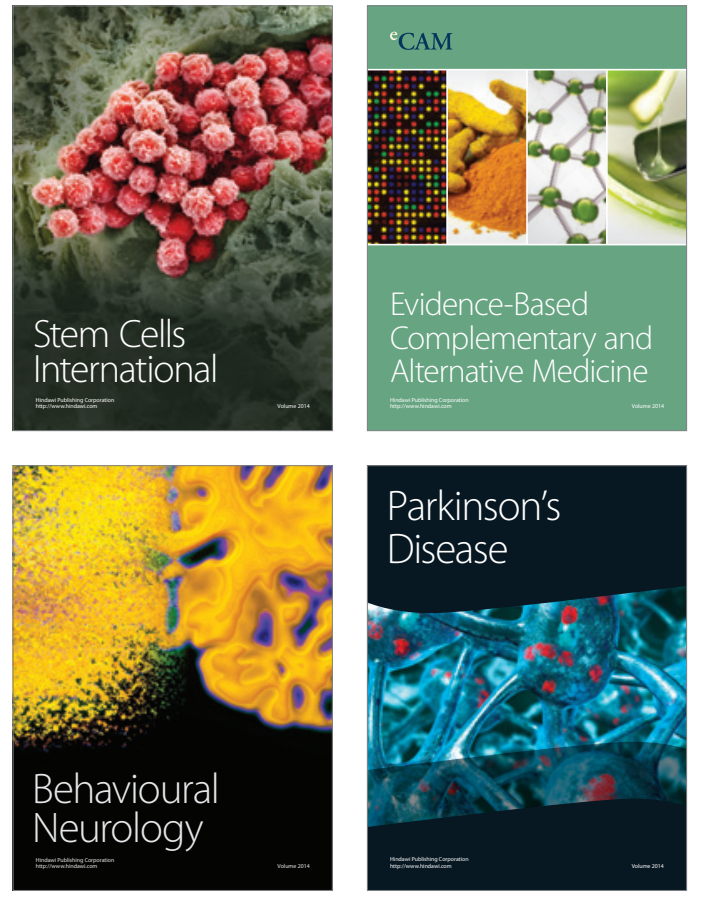
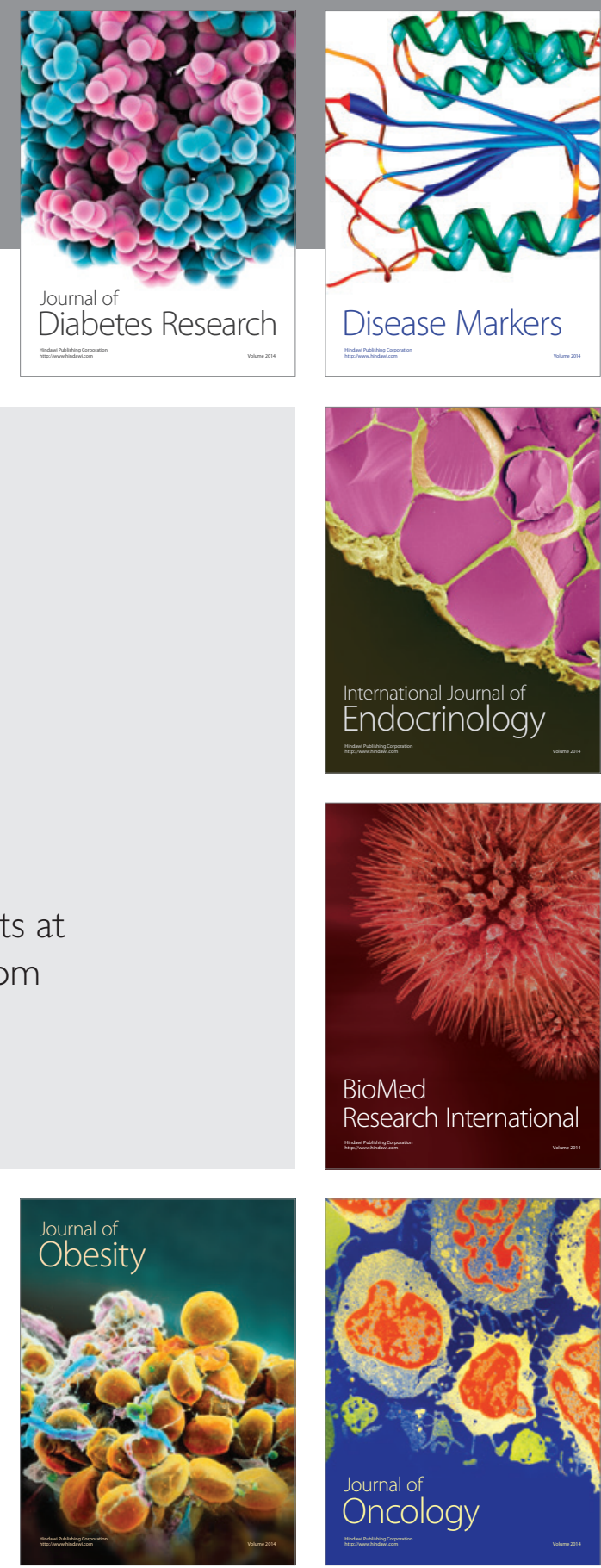

Disease Markers
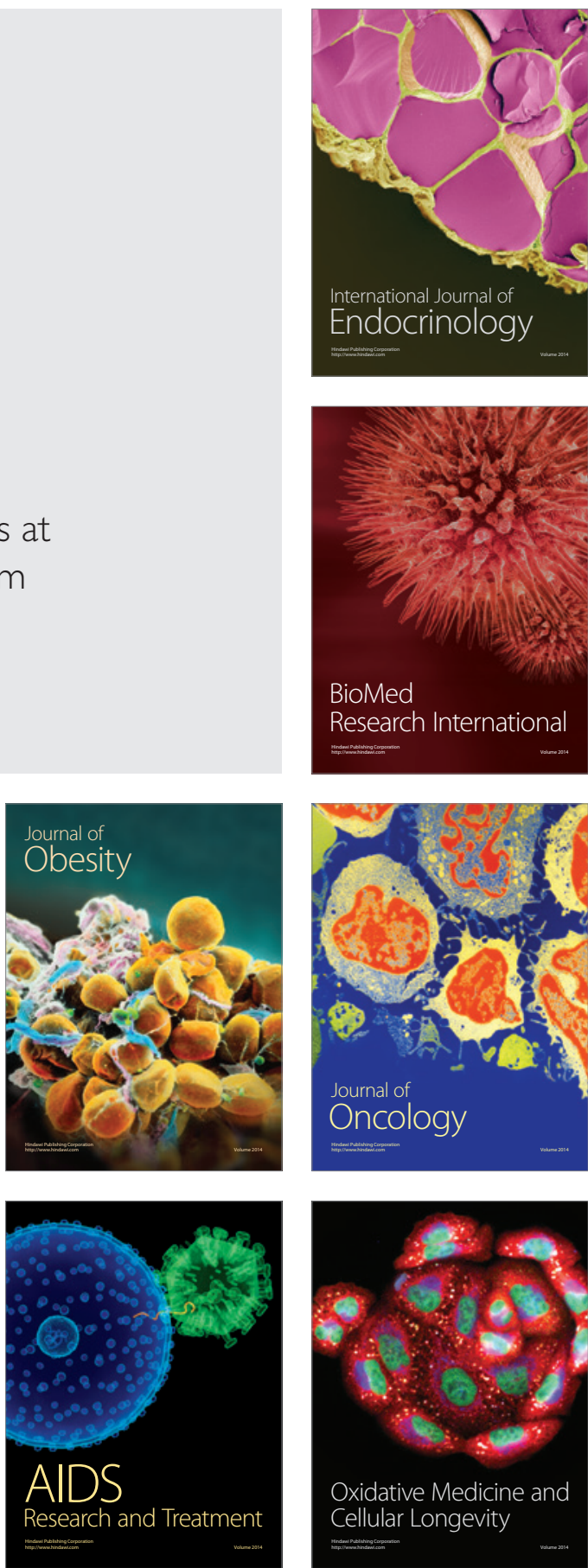